\title{
Changes in inequality in utilization of maternal health care: evidence from skilled birth attendance in Mauritania for the period 2007-2015
}

\author{
Taleb El Hassen, M.Vadel, Cabases Juan, Zine Eddine El Idrissi M. Driss
}

\begin{abstract}
Background: The presence of a skilled health professional at delivery is critical to reduce infant and maternal mortality. Health development plans and strategies, especially in developing countries, consider equity in access to maternal health care services as a priority. This study aimed to measure and analyze the inequality in the use of skilled births attendance services in Mauritania. The study identifies the inequality determinants and to explore its changes over the period 2007-2015.

Methods: The concentration curve, concentration index, decomposition of the concentration index and Oaxaca-type decomposition technique were performed to measure socio-economics related inequalities in skilled birth attendance services utilization and identify contribution of different determinants to such inequality as well as the changes in inequality overtime using data from Mauritania Multiple Indicator Cluster Surveys (MICS) 2007, 2011 and 2015.

Results: The concentration index for skilled birth attendance services utilization dropped from 0.6324 [P $<0.001]$ in 2007 to 0.5852 [P $<0.001]$ in 2015. Prenatal care, household wealth Status and urban-rural location made the biggest contributions to socio-economic related inequalities. Decomposition of the concentration index and Oaxaca-type decomposition revealed changes prenatal care, rural-urban location made positive contributions to decline in inequality. However, alternation in household wealth score, woman's age, her education level and the number of living children pushed the equality toward deterioration.

Conclusion: Clearly, the pro-rich inequality in skilled birth attendance is high in Mauritania despite a slight decrease during the study period. Policy actions on eliminating urban-rural and wealth index disparity should target increase access to skilled birth attendance. Multisectoral Policy actions is needed to improve social determinants of health and to remove health system bottlenecks including socio-economic empowerment of women and girls, enhancing availability and affordability of Reproductive and Maternal Health commodities, improving availability of obstetrical providers in rural area, promoting a better distribution and quality of health infrastructure particularly health posts and health centers, and replacing user fees by an equitable, efficient and sustainable financing scheme under an universal health coverage vision.
\end{abstract}

Keywords: Skilled birth attendance, Inequality, Concentration curve, Concentration index, Oaxaca decomposition, Mauritania 


\section{Background}

Economic performance in Mauritania has improved substantially over the past fifteen years. The country underwent fast economic growth from 2008 to 2014, convoyed by significant progress in household welfare. Thus, there was a sharp decline in poverty rate, which fell from $44.5 \%$ of the country's population in 2008 to $33 \%$ in 2014 [1,2]. These improvements are explained by recoveries in production, productivity, and income in rural areas [3]. However, Mauritania's health system continues to perform poorly on indicators of maternal and child health care. The maternal mortality rate (MMR), with 582 deaths per 100,000 live births in 2015, was far from the Milinium Development Goals (MDG) target -232 deaths per 100,000 live births-[4,5], and is also among the highest in the region, being the average for sub-Saharan Africa 542[6].

The challenge for the Mauritanian health sector was always to maximize access to health services considering the constraints linked to a very low population density estimated at 4.3 inhabitants per $\mathrm{km} 2$, against an average of 44.9 in sub-Saharan Africa [7]. The key strategy to improve access was extending the coverage of the basic infrastructure to bring $91 \%$ of the population to access within $5 \mathrm{~km}$ of a post or a functional health center and have access to the three most common health service packages essential [8]. However, geographic access to health services is still at a level of $67.3 \%$ with disparity among the regions [2]. The poorest regions are the region with the lowest geographic access to services. Poor road conditions result in high transport costs and long travel times, especially during emergencies, such as delivery cases. In urban centers such as Capital Nouakchott, the problem of geographic accessibility to health services exists, but to a much lesser extent and the private sector help alleviate this problem in these centers.

The availability of basic health services such as Reproductive, Maternal, Neonatal and Child Health (RMNCH) services remains low and often fall below 60\% [9]. For example, $41 \%$ of public health facilities and $80 \%$ of private health facilities do not have assisted delivery services to offer to the covered population [9].

Like other sub-Saharan countries, numerous strategies for reducing financial barriers have been attempted such as community-based health insurance (CBHI), indigence fund, obstetrical risk insurance scheme and compulsory health insurance through the national health insurance fund. Furthermore, private insurance companies are generally contracted by large enterprises for the benefit of their employees, but their coverage remains limited to the affluent segments of the population. The obstetrical risk insurance scheme is based on a set of basic gynecological and obstetric services provided by health facilities against a contribution equivalent to approximately \$20 USD, enabling pregnant women to follow their pregnancy and to give birth in the public health facility, whatever the course of the pregnancy, childbirth and possible complications, including caesarean section. Despite these efforts, significant financial barriers persist. The communitybased health insurance is limited to a few experiences in two districts with extremely low coverage. Waelkens Maria-Pia et al 2017 [10] found that the Membership of the CBHI remained far too low to be considered as a potential strategy on the path towards universal health coverage in Mauritania. Aline Philibert et al. 2017 [11] also found that the obstetrical risk insurance scheme availability has not attracted all pregnant women towards better access to facility-based health care and it appears that some strata of women gained more than others. In addition, the national health insurance fund, which covers around seventy percent of health care costs, barely manages to cover $12 \%$ of the population in 2019 [12]. The population covered is mainly civil servants and the formal private sector. Thus, households continue spend large proportions of out-of-pocket health care expenditures up to $51 \%$ of total health expenditure in 2016 [13]. 
Equity in access and use of maternal health care services is considered a priority by most health development plans and strategies in sub-Saharan countries, which have committed to reducing maternal mortality to 70 per 100,000 live births by 2030, in line with the Sustainable Development Goals [14]. In this context, the Mauritanian development strategy 2016-2030, called the strategy for accelerated Growth and Shared prosperity which corresponds to that of the 2030 agenda for suspensible development as well as Mauritanian national plan for healthcare development 2012-2020 both tried to promote access to key quality maternal health interventions, particularly to skilled birth attendance (SBA), which is considered a key strategy for reducing perinatal, neonatal and maternal deaths [15-16]. SBA takes place when a midwife, physician, obstetrician or nurse provides essential and emergency health care services to women and their newborns during pregnancy, childbirth and the postpartum period [17]. Progress in raising the coverage of births attended by skilled health personnel has been slow since 2007: 60.9 in 2007 to 69.3 percent in 2015, reflecting lack of universal access to maternal car [15].

The present study contributes to the literature that examines the trends and degrees of inequalities in the utilization of skilled birth attendance. Previous studies conducted in Kenya, Nigeria, Bangladesh, Namibia [18-21] and other developing countries [22-34] have indicated that socio-economic status, mother education level, urban-rural residence, birth order, insurance status play keys role in explaining the differences in utilization and the levels of inequality in skilled birth attendance and maternal health care utilization. A few studies have decomposed income inequalities and measured change in inequality in maternal health care use in sub-Sahara [35,36], while, to the best of our knowledge, no such studies have been conducted in Mauritania.

In order to fill theses knowledge gap, the present study intended to quantify the trends in socioeconomics related inequality in skilled birth attendance in Mauritania, and to determine the contribution of the determinants of the inequality, by means of decomposition analysis, decomposing changes in inequality using Oaxaca-type decomposition. Based on the most recent and the oldest data available, the study covers the period 2007 and 2015. This period coincides with the end of the Millennium Development Goals 2015 and the mid-term review of the Mauritanian national plan for healthcare development 2012-2020. The results of our analysis may contribute to evaluate the strategies developed by the Mauritanian government to promote equity in the access to maternal health care, and also to inform public policies aimed at effectively reducing MMR.

\section{Materials and methods}

\subsection{Data sources and sample}

The present study was based on publicly available data from 2007 to 2015 of Mauritanian Multiple Indicator Cluster Surveys (MICS). The MICS is a nationally representative survey of households, women of childbearing age, children under 5 and men aged 15 to 49, which collects information about reproductive, maternal, neonatal and child health care. The surveys also cover early childhood development, education and literacy. The results of the survey are used to monitor and evaluate a range of indicators in the areas of Reproductive, Maternal, Neonatal and Child Health, education, child protection and HIV/AIDS included in the Sustainable Development Goals and the Mauritanian Strategy for Accelerated Growth and Shared Prosperity 2016-2030 and National Health Development Strategy 2012-2020 such as Skilled birth attendance and maternal mortality. The surveys are typically conducted and implemented by the National Statistical Office at a 5-year interval $[37,38]$. 
The final sample consisted of 11,000 households. Interviews were completed with a total of 12,549 women aged 15-49 years old from the selected households [37].

In 2007, the sample included in the MICS was obtained by using a two-stage stratified cluster sampling approach, where the primary units were the census districts (CD), as defined in the 2000 census, and the secondary units were formed by the households. The final sample consisted of 11,000 households. Interviews were completed with a total of 12,549 women aged 15-49 years old from the selected households [38].

On the other hand, the sample included in the MICS 2015 was obtained by using a three-stage stratified cluster sampling approach, where the primary units are the census districts of the 2013 master sample. The secondary units of the survey are segments, or the subdivisions of the primary units established during the constitution of the 2013 master sample. The tertiary units of the survey are the households that make up the segments. The final sample consisted of 11,985 households with response rates of $97 \%$. Interviews were completed with a total of 14,342 women aged 15-49 years old from the selected households.

The overall sample size of the two round differs slightly considering that the two surveys use two different censuses of the population that of 2000 and that of 2013 with a number of sampling areas, sampling units and the size of the final clusters different.

The final sample of the study used a total of women aged 15-49 years old 3,539 in 2007 and 4,172 in 2015 from households selecting those who had given birth in the last two years preceding the survey

\subsection{Measuring and decomposing socio-economic inequalities in SBA}

\subsubsection{Measuring inequality}

In order to measure inequality, we used the concentration curve (CC) and concentration index as a conventional method for computing and decomposing socio-economic related inequality in skilled birth attendance. The CC plots shares of the SBA against quantiles of wealth index. The $\mathrm{CI}$ is directly related to concentration curve (CC) and represents the twice area between the $\mathrm{CC}$ and $45^{\circ}$ line or equality line [40]. The CI can be measured following Wagstaff et al (1991) [40] as follows:

$$
C I=\frac{2}{n^{2} \bar{y}} \sum_{i=1}^{n} y_{i} r_{i}
$$

Where $y$ denote the variable of interest or SBA, $\bar{y}$ designates its mean and $r_{i}$ indicates the fractional rank of each individual of the population in terms of wealth index. The value of CI can range from -1 to +1 . A positive value suggests a pro-rich concentration of skilled birth attendance and vice versa. A positive value would be presented below the line of equality $\left(45^{0}\right.$ line) while the negative value would lie above the line of equality. If the value of CI is zero, this indicates that no income related inequality in the distribution of $y$ and the $\mathrm{CC}$ will coincide with the line of equality.

Since the variable of interest in this paper is binary variable (whether the delivery was assisted by skilled health professional or not), a normalization of CI is needed so that the CI can vary from -1 to +1 or from $\bar{y}-1$ to $1-\bar{y}$. Two approaches of normalization exist: Wagstaff and Erreygers [40-43]. There has been much literature debate about the appropriate normalization to apply when dealing with binary variables [44-45]. We use Erreygers normalization which can be represented as follows: 
Where $y^{\max }$ and $y^{\min }$ are the bounds of $y$.

$$
C I E=\frac{4 \bar{y}}{y^{\max }-y^{\min }} C I
$$

\subsubsection{Decomposing inequality}

When there is a linear relationship between health outcome $(y)$ and a set of k explanatory variables $x[46,50]$ this can be specified as follows:

$y=\alpha+\sum_{k} \beta_{k} \bar{x}_{k}+\varepsilon$

The CI can be expressed as weighted sum of partial concentration indices for the explanatory variables of inequality, being the weight the elasticity of $\gamma$ with respect to $x_{k}[46,50]$ :

$C I E=\sum_{k}\left(\frac{\beta_{k} \bar{x}_{k}}{\bar{y}}\right) C I E_{k}+\frac{G C I E_{\varepsilon}}{\mathrm{y}}$

Where $\bar{x}$ is the mean of $x_{k}, C I E_{k}$ is the concentration index for $x_{k}$ and $G C I E_{\varepsilon}$ is the generalized concentration index for the term $(\varepsilon)$.

Considering the dichotomous characters of SBA, a non-linear model is required. We used probit models to measure all the estimates, then, a linear approximation was performed for the decomposition analysis based on Erreyger's normalized concentration index [44,45] as follows:

$C I E=4 \sum_{k}\left(\beta_{k}^{m} \bar{x}_{k}\right) C I E_{k}+G C I E_{\varepsilon}$

Where $\beta_{k}^{m}$ represent the partial effects $\left(\frac{d y}{d x_{k}}\right)$ evaluated at the sample means.

\subsubsection{Decomposing changes in inequality}

The change of CIE over the period 2007- 2015 can be expressed as follow: $\triangle C I E_{y}=C I E_{y 2015}-C I E_{y 2007}$ (4)

To examine the drivers of changes in equality in skilled birth attendance in 2007 and 2015 we applied the Oaxaca decomposition to the eq 3 . This leads to the following

$\triangle C I E=\sum_{k} \eta_{k 2015}\left(C I E_{k 2015}-C I E_{k 2007}\right)+\sum_{k} C I E_{k 2007}\left(\eta_{k 2015}-\eta_{k 2007}\right)+\Delta\left(\frac{G C I E_{\varepsilon t}}{\bar{y}_{t}}\right)$

(5)

Or Alternatively, by:

$\triangle C I E=\sum_{k} \eta_{k 2007}\left(C I E_{k 2015}-C I E_{k 2007}\right)+\sum_{k} C I E_{k 2015}\left(\eta_{k 2015}-\eta_{k 2007}\right)+\triangle\left(\frac{G C I E_{\varepsilon t}}{\bar{y}_{t}}\right)$

(6)

Where $\eta_{k t}=\left(\beta_{k}^{m} \bar{x}_{k}\right)$ is the elasticity of $y$ with respects to $k^{\text {th }}$ determinant in year $t$.

Aside from the contribution of unexplained factors $\triangle\left(\frac{G C I E_{\varepsilon t}}{\bar{y}_{t}}\right)$, the changes of $C I E_{y}$ can be explained by changes in elasticities $\left(\eta_{k 2015}-\eta_{k 2007}\right)$ and by changes in the concentration index $\left(C I E_{k 2015}-C I E_{k 2007}\right)$ or both. The elasticity of $k^{\text {th }}$ determinant $\eta_{k t}=\left(\beta_{k}^{m} \bar{x}_{k}\right)$, can change due to variations in any of its components, namely $\beta_{k}^{m}$ and $\bar{x}_{k}$. The concentration index $\left(C I E_{k 2007}, C I E_{k 2015}\right)$ can change due to variations of its $k^{\text {th }}$ determinant.

\subsection{Definition of variables}

\section{Outcome variable.}


Our variable of interest is birth attendance by qualified health professional. The outcome variable or Skilled birth attendant is "an accredited health professional — such as a midwife, doctor or nurse - who has been educated and trained to proficiency in the skills needed to manage normal (uncomplicated) pregnancies, childbirth and the immediate postnatal period, and in the identification, management and referral of complications in women and newborns"[17]. Among the respondents who declared having had a childbirth in the past two years preceding the survey, our variable of interest was asked as follows: "Who assisted you during the delivery?". The possible responses options were doctor, nurse, midwife, auxiliary birth attendant, traditionally birth attendant, community health worker, parent/friend, others or no one. Based on WHO definition, outcome variable was dichotomized to 1 if the birth was attended by a doctor, a nurse or a midwife, and 0 otherwise.

The following explanatory variables have been selected based on previous studies [18-34], and their availability in the dataset.

\section{Socio-economic indicator}

MICS survey lacks information about household income or consumption as a measure of living standards. Therefore, household wealth index (WI) was built using Principal Component Analysis (PCA). The variables included in the PCA were the availability of water and sanitation, radio, television, satellite dish, landline telephone, mobile phone, refrigerator, oven stove, air conditioner, fan, washing machine, electricity generator, solar panel, watch, bicycle, motorcycle or scooter, cart, car/truck, motor boat, computer and internet connections. Each household in the total sample is then assigned a wealth score based on their assets held and on the final factor scores obtained. We used a household wealth index (WI) provided in MICS to depict socio-economic status and living standards. For calculation concentration index, WI was used as continuous variable, and for the decomposition analysis, WI was categorized into quintiles with first quintile representing the poorest and the fifth quintile representing richest.

\section{Social determinants of SBA}

Socio-demographic characteristics were proxied by women's age (15-24,25-34,35-44, 45-49), maternal education level (no education, primary, secondary and higher), residence place (urban, rural), region ( Nouakchott, Hodh Charghy ....), wealth quintile (first quintile, second quintile, third quintile, fourth quintile, fifth quintile). Individual weights were applied to data to make the sample representative of the whole population. All analyses were conducted in StataSE 15 (C. The concentration indices were calculated by using the conindex command in Stata[51].

\section{Results}

\subsection{Descriptive Statistics}

The majority of the study respondents were 15-24 years old, rural resident, and from Nouakchott region both in 2007 and 2015 (Table 1). About 57.12\% of the deliveries were attended by skilled health providers in 2007 against $64,41 \%$ in 2015 . A breakdown by various maternal and household characteristics displays the changes in SBA by the various characteristics. Most pronounced differences are seen by the household wealth quintiles, urban rural residency and women's level of education. Skilled birth attendance in the richest quintile is about $70 \%$ higher in both surveys than in the poorest quintile. The average of skilled 
attendance among educated women is almost twice that of women with no education in both surveys (Table 1) . Furthermore, the weighted means of SBA in urban areas is twice that of rural areas.

In both surveys, the use of skilled birth attendants is over $80 \%$ in Nouakchott, Nouadibou, Trarza, Tiris-Zemour and Inchiri Regions, while the lowest (about 25-50\%) is seen in Guidimagha, Hodh Charghy, Hodh Gharby and Gorgol. In 2015, parturient women in Nouakchott, Tiris-Zemour and Nouadibou utilize the services of skilled attendants by more than $64 \%$ compared to those living in Guidimagha. In 2015, the use of skilled birth was below the national average of $64.41 \%$ in six of the thirteen regions.

Table 1 Characteristics of the sample

\begin{tabular}{|c|c|c|c|c|c|c|}
\hline & \multicolumn{3}{|c|}{2007} & \multicolumn{3}{|c|}{2015} \\
\hline & $N=3539$ & $\%$ & $\begin{array}{l}\text { SBA weighted } \\
\text { mean }\end{array}$ & $N=4172$ & $\%$ & $\begin{array}{c}\text { SBA weighted } \\
\text { mean }\end{array}$ \\
\hline \multicolumn{7}{|l|}{ Age } \\
\hline $15-24$ & 1168 & $33 \%$ & $63 \%$ & 1195 & $29 \%$ & $66 \%$ \\
\hline $25-34$ & 1583 & $45 \%$ & $55 \%$ & 1958 & $47 \%$ & $65 \%$ \\
\hline $35-44$ & 736 & $21 \%$ & $54 \%$ & 946 & $23 \%$ & $62 \%$ \\
\hline $45-49$ & 53 & $1 \%$ & $31 \%$ & 73 & $2 \%$ & $50 \%$ \\
\hline \multicolumn{7}{|l|}{ Birth order } \\
\hline $\mathbf{0}$ & 34 & $1 \%$ & $80 \%$ & 34 & $1 \%$ & $68 \%$ \\
\hline 1 & 644 & $18 \%$ & $70 \%$ & 789 & $19 \%$ & $77 \%$ \\
\hline 2 & 633 & $18 \%$ & $65 \%$ & 731 & $18 \%$ & $70 \%$ \\
\hline 3 & 569 & $16 \%$ & $56 \%$ & 682 & $16 \%$ & $69 \%$ \\
\hline 4 & 1651 & $47 \%$ & $49 \%$ & 1935 & $46 \%$ & $56 \%$ \\
\hline \multicolumn{7}{|l|}{ Prenatal } \\
\hline yes & 2860 & $81 \%$ & $66 \%$ & 3641 & $87 \%$ & $70 \%$ \\
\hline no & 679 & $19 \%$ & $18 \%$ & 531 & $13 \%$ & $27 \%$ \\
\hline \multicolumn{7}{|c|}{ Place of residence } \\
\hline urban & 1509 & $43 \%$ & $86 \%$ & 1877 & $45 \%$ & $87 \%$ \\
\hline rural & 2030 & $57 \%$ & $36 \%$ & 2295 & $55 \%$ & $46 \%$ \\
\hline \multicolumn{7}{|l|}{ Region } \\
\hline Hodh charghy & 423 & $12 \%$ & $34 \%$ & 502 & $12 \%$ & $40 \%$ \\
\hline Hodh Gharby & 341 & $10 \%$ & $27 \%$ & 412 & $10 \%$ & $38 \%$ \\
\hline Assaba & 371 & $10 \%$ & $35 \%$ & 479 & $11 \%$ & $55 \%$ \\
\hline Gorgol & 341 & $10 \%$ & $32 \%$ & 508 & $12 \%$ & $49 \%$ \\
\hline Brakna & 331 & $9 \%$ & $58 \%$ & 428 & $10 \%$ & $82 \%$ \\
\hline Trarza & 333 & $9 \%$ & $80 \%$ & 299 & $7 \%$ & $82 \%$ \\
\hline Adrar & 61 & $2 \%$ & $64 \%$ & 20 & $0 \%$ & $66 \%$ \\
\hline Nouadibou & 119 & $3 \%$ & $86 \%$ & 137 & $3 \%$ & $96 \%$ \\
\hline Tagant & 76 & $2 \%$ & $39 \%$ & 23 & $1 \%$ & $55 \%$ \\
\hline Guidimagha & 177 & $5 \%$ & $25 \%$ & 329 & $8 \%$ & $25 \%$ \\
\hline Tirs-Zemour & 63 & $2 \%$ & $88 \%$ & 20 & $0 \%$ & $89 \%$ \\
\hline Inchiri & 8 & $0 \%$ & $85 \%$ & 5 & $0 \%$ & $81 \%$ \\
\hline Nouakchott & 896 & $25 \%$ & $90 \%$ & 1010 & $24 \%$ & $95 \%$ \\
\hline
\end{tabular}




\begin{tabular}{lcccccc} 
Education & & & & & $0 \%$ \\
No & 1002 & $28 \%$ & $40 \%$ & 1130 & $27 \%$ & $50 \%$ \\
Primary & 1992 & $80 \%$ & $58 \%$ & 2358 & $76 \%$ & $61 \%$ \\
Secondary & 451 & $18 \%$ & $88 \%$ & 655 & $21 \%$ & $89 \%$ \\
University & 39 & $2 \%$ & $89 \%$ & 96 & $3 \%$ & $90 \%$ \\
Wealth index & & & & & & \\
Q1 (Poorest) & 857 & $24 \%$ & $19 \%$ & 880 & $21 \%$ & $25 \%$ \\
Q2 & 694 & $20 \%$ & $36 \%$ & 875 & $21 \%$ & $48 \%$ \\
Q3 & 657 & $19 \%$ & $67 \%$ & 829 & $20 \%$ & $71 \%$ \\
Q4 & 681 & $19 \%$ & $86 \%$ & 838 & $20 \%$ & $90 \%$ \\
Q5 & 649 & $18 \%$ & $90 \%$ & 751 & $18 \%$ & $94 \%$ \\
Total & 2022 & & $57.12 \%$ & 2687 & & $64.41 \%$ \\
\hline
\end{tabular}

\subsection{Measuring inequality}

Concentration curves of skilled birth attendance use for both surveys lie below the line of equality, indicating that skilled birth attendance care is more frequently used among richer women. Moreover, the corrected concentration indices were positive $0.6324[\mathrm{P}<0.001]$ in 2007 and $0.5852[\mathrm{P}<0.001]$ in 2015 , indicating that the better-off women were significantly more likely to be attended by skilled professionals at the time of delivery than their poorer counterparts. (Table 2) (see Fig. 1).

Figure 1. Concentration curves of SBA (2007-2015).

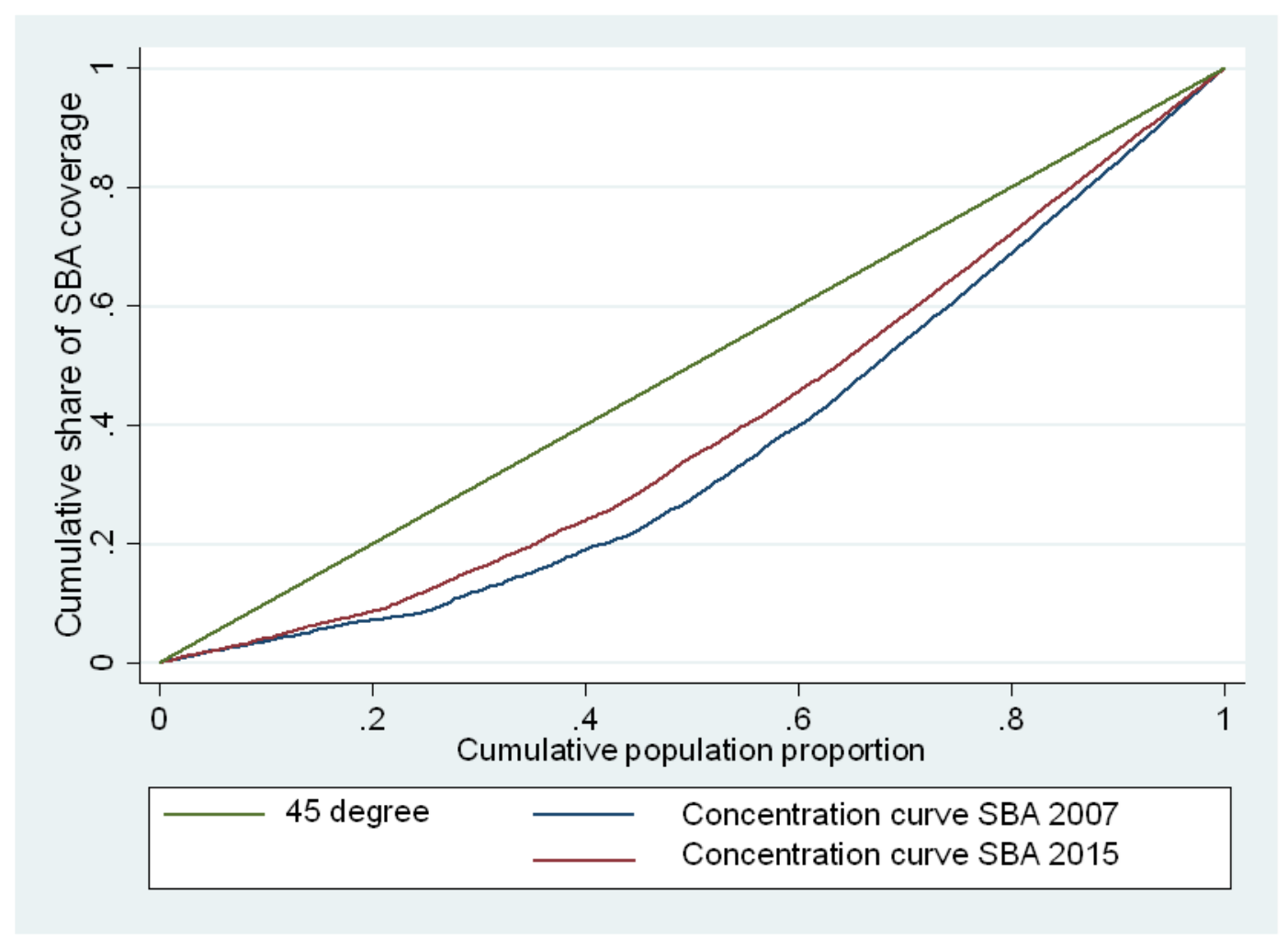




\subsection{Decomposition of SBA inequalities}

The marginal effect estimates in both surveys (2007 and 2015) show that living in rural area, in region such as Hodh Charghy, Hodh Gharby, Assaba, Gorgol, Guidimagha, being poorest (Q1) or poor (Q2) were associated significantly with lower use of skilled birth attendance (Marginal effects dy/dx column) while prenatal care use and having a secondary school level were associated significantly with high use of skilled birth attendance. Also, 35-49 year-old, living in Tagant and having a primary education level were less relevant in 2007 but their significance increased between 2007 and 2015. Inversely, having one or more living children were relevant in 2007 but their significance decreased in 2015 (Marginal effects dy/dx column).

Moreover, regions showed different effects from one period to another: in nine of them it was observed a noticeable decrease in the partial effect, whilst a remarkable increase was registered in three regions namely Assaba, Brakna and Tagant.

Results of decomposition of SBA inequalities demonstrate that the concentration index associated with skilled birth attendance is positive in both surveys ( 0.6324 in 2007 and 0.5852 in 2015) and thus describes skilled birth attendance inequalities in favor of the wealthiest women. The decrease in the concentration index in 2015 indicates a slight decrease in the inequalities in skilled birth attendance between 2007 and 2015. The elasticity reveals the sensitivity of SBA to a change in the determinants. Variable with a positive elasticity suggests that women with this characteristic are more likely to receive skilled birth attendance at delivery. The concentration indices were estimated for each regressor; a positive value implies that the variable has a pro-rich inequality; similarly negative signs for corrected concentration indices (CIE column) indicate that the explanatory variables had a pro-poor distribution. The results in both surveys show a positive concentration index for women who used antenatal care, having a secondary school level, having one or two living children, living in urban area such as Nouadibou and Trarza. This means that skilled birth attendance was concentrated more among the relatively wealthier segment of the women with these characteristics. In contrast, variables such as living in rural area, living in Hodh charghy, Assaba, Hodh Gharby, Gorgol, Guidimagha, Brakna, being poorest (Q1) or poor (Q2) had significantly negative CIEs, indicating that these variables were more prevalent among the poor (CIE column).

The concentration indices associated with the (35-49) age groups are negative indicating that they are concentrated in the lowest quintiles groups, whereas women with 46 years and older are concentrated in the higher income categories.

According to our results, inequality in skilled birth attendance in both periods was mainly explained by the direct effect of antenatal care use, living in rural area, and economics status of household (i, e. being poorest (Q1) or poor (Q2)). The use of antenatal care contributes up to $33 \%$ of the total inequality in 2007 and for $15.1 \%$ in 2015 showing a decrease in its contribution more than the half in 2015. Living in rural area was the second important factor in explaining the inequality in skilled birth attendance in both periods. It accounted for $29.8 \%$ of the total inequality in 2007 and for $20.1 \%$ in 2015 revealing a decrease in its contribution in 2015. The contribution of household economics status shows an increase between the two surveys. For example, being poorest (Q1) or poor (Q2) accounted respectively for $21.8 \%$ and $4.8 \%$ of the total inequality in 2007 and for $23.2 \%$ and $5.8 \%$ in 2015 .

Overall, the rank of the key determinants slightly changed in 2015; being poorest (Q1) was the main determinant $(23.5 \%)$, followed by living in rural area $(20 \%)$ and antenatal care use came in the third position (15.7\%) and the number of living children four or more (9.4\%). All these 
factors tended to favor the better-off in both periods. This is also the case of secondary level of education, whose contribution increase from $2.68 \%$ to $4.6 \%$.

The determinants included in the model explained $112 \%$ of the overall socio-economic inequality in skilled birth attendance. About $-12 \%$ of the overall inequality was due to the residuals (i.e., the inequality left unexplained). The unexplained part of inequality, although higher in the final year compared to the beginning of the period, was low in both analyzed years, what indicates a good specification of the probit models. 
Table 2. Decomposition of inequality in access to SBA in Mauritania and total change 2007-2015

\begin{tabular}{|c|c|c|c|c|c|c|c|c|c|c|c|}
\hline \multirow[b]{3}{*}{ Variables } & \multicolumn{5}{|l|}{2007} & \multicolumn{6}{|l|}{2015} \\
\hline & \multicolumn{5}{|c|}{$\mathrm{N}=3,539$} & \multicolumn{6}{|c|}{$\mathrm{N}=4,172$} \\
\hline & $\begin{array}{l}\text { Marginal } \\
\text { effects dy/dx }\end{array}$ & elasticity & CIE & $\begin{array}{c}\text { Absolute } \\
\text { contribution }\end{array}$ & $\begin{array}{c}\text { Percentage } \\
\text { Contribution (\%) }\end{array}$ & $\begin{array}{l}\text { Marginal } \\
\text { effects dy/dx }\end{array}$ & elasticity & CIE & $\begin{array}{c}\text { Absolute } \\
\text { contribution }\end{array}$ & $\begin{array}{c}\text { Percentage } \\
\text { Contribution }(\%)\end{array}$ & Change \\
\hline \multicolumn{12}{|l|}{ Age } \\
\hline $15-24$ & Ref. & & & & & Ref. & & & & & \\
\hline $25-34$ & -0.0249 & -0.0445 & 0.0167 & -0.0007 & $-0.12 \%$ & 0.0281 & 0.0527 & 0.0718 & 0.0038 & $0.6 \%$ & 0.0045 \\
\hline $35-44$ & 0.0495 & 0.0412 & -0.0437 & -0.0018 & $-0.28 \%$ & $0.0712 * *$ & 0.0646 & -0.0398 & -0.0026 & $-0.4 \%$ & -0.0008 \\
\hline $45-49$ & -0.0663 & -0.0040 & -0.0200 & 0.0001 & $0.01 \%$ & $0.1136^{*}$ & 0.0080 & -0.0212 & -0.0002 & $0.0 \%$ & -0.0002 \\
\hline \multicolumn{12}{|c|}{ Birth order } \\
\hline Child (0) & Ref. & & & & & Ref. & & & & & \\
\hline Child (1) & $-0.1908 *$ & -0.1392 & 0.1054 & -0.0147 & $-2.32 \%$ & -0.0226 & -0.0171 & 0.1077 & -0.0018 & $-0.3 \%$ & 0.0128 \\
\hline Child (2) & $-0.2391 * *$ & -0.1713 & 0.0832 & -0.0143 & $-2.25 \%$ & -0.0712 & -0.0499 & 0.0650 & -0.0032 & $-0.6 \%$ & 0.0110 \\
\hline Child (3) & $-0.2661 * *$ & -0.1714 & 0.0097 & -0.0017 & $-0.26 \%$ & -0.0801 & -0.0524 & 0.0624 & -0.0033 & $-0.6 \%$ & -0.0016 \\
\hline Child (4+) & $-0.2807 * *$ & -0.5251 & -0.2033 & 0.1068 & $16.88 \%$ & -0.1251 & -0.2321 & -0.2323 & 0.0539 & $9.2 \%$ & -0.0528 \\
\hline \multicolumn{12}{|l|}{ Prenatal } \\
\hline yes & $0.2052^{* * *}$ & 0.6632 & 0.3234 & 0.2145 & $33.91 \%$ & $0.1386^{* * *}$ & 0.4837 & 0.1823 & 0.0882 & $15.1 \%$ & -0.1263 \\
\hline & Ref. & & & & & Ref. & & & & & \\
\hline \multicolumn{12}{|c|}{ Place of residence } \\
\hline Rural & $-0.1001^{* * *}$ & -0.2296 & -0.8207 & 0.1884 & $29.80 \%$ & $-0.0626 * *$ & -0.1378 & -0.8494 & 0.1170 & $20.0 \%$ & -0.0714 \\
\hline Urban & Ref. & & & & & Ref. & & & & & \\
\hline \multicolumn{12}{|l|}{ Region } \\
\hline $\begin{array}{l}\text { Hodh } \\
\text { charghy }\end{array}$ & $-0.1506^{* * *}$ & -0.0719 & -0.1999 & 0.0144 & $2.27 \%$ & $-0.1947 * * *$ & -0.0937 & -0.2172 & 0.0204 & $3.5 \%$ & 0.0060 \\
\hline $\begin{array}{l}\text { Hodh } \\
\text { Gharby }\end{array}$ & $-0.1715^{* * *}$ & -0.0660 & -0.1580 & 0.0104 & $1.65 \%$ & $-0.1947 * * *$ & -0.0768 & -0.1518 & 0.0117 & $2.0 \%$ & 0.0012 \\
\hline Assaba & $-0.1548 * * *$ & -0.0650 & -0.1616 & 0.0105 & $1.66 \%$ & $-0.1221 * * *$ & -0.0561 & -0.1186 & 0.0067 & $1.1 \%$ & -0.0038 \\
\hline Gorgol & $-0.1552 * * *$ & -0.0598 & -0.1343 & 0.0080 & $1.27 \%$ & $-0.1951^{* * *}$ & -0.0951 & -0.1281 & 0.0122 & $2.1 \%$ & 0.0042 \\
\hline
\end{tabular}




\begin{tabular}{|c|c|c|c|c|c|c|c|c|c|c|c|}
\hline Brakna & -0.0681 & -0.0254 & -0.0537 & 0.0014 & $0.22 \%$ & 0.0235 & 0.0096 & -0.0355 & -0.0003 & $-0.1 \%$ & -0.0017 \\
\hline Trarza & 0.0196 & 0.0074 & 0.0697 & 0.0005 & $0.08 \%$ & -0.0634 & -0.0182 & 0.0506 & -0.0009 & $-0.2 \%$ & -0.0014 \\
\hline Adrar & -0.0153 & -0.0011 & 0.0009 & 0.0000 & $0.00 \%$ & -0.1386 & -0.0026 & 0.0016 & 0.0000 & $0.0 \%$ & 0.0000 \\
\hline Nouadibou & -0.0784 & -0.0105 & 0.0883 & -0.0009 & $-0.15 \%$ & 0.0681 & 0.0089 & 0.0947 & 0.0008 & $0.1 \%$ & 0.0018 \\
\hline Tagant & -0.0893 & -0.0077 & -0.0216 & 0.0002 & $0.03 \%$ & $-0.1564^{*}$ & -0.0034 & -0.0022 & 0.0000 & $0.0 \%$ & -0.0002 \\
\hline Guidimagha & $-0.2419 * * *$ & -0.0484 & $-0,0664$ & 0.0032 & $0.51 \%$ & $-0.3264 * * *$ & -0.1028 & -0.1114 & 0.0114 & $2.0 \%$ & 0.0082 \\
\hline $\begin{array}{l}\text { Tirs- } \\
\text { Zemour }\end{array}$ & -0.0140 & -0.0010 & 0.0392 & 0.0000 & $-0.01 \%$ & -0.0978 & -0.0019 & 0.0140 & 0.0000 & $0.0 \%$ & 0.0000 \\
\hline Inchiri & 0.0009 & 0.0000 & 0.0033 & 0.0000 & $0.00 \%$ & -0.1298 & -0.0006 & 0.0027 & 0.0000 & $0.0 \%$ & 0.0000 \\
\hline Nouakchott & Ref. & & & & & Ref. & & & & & \\
\hline \multicolumn{12}{|c|}{ Education Level } \\
\hline Primary & 0.0258 & 0.0467 & 0.0466 & 0.0022 & $0.34 \%$ & $0.0479 *$ & 0.0928 & -0.1097 & -0.0102 & $-1.7 \%$ & -0.0123 \\
\hline Secondary & $0.0704 * *$ & 0.0508 & 0.3340 & 0.0170 & $2.68 \%$ & $0.0831 * * *$ & 0.0698 & 0.3569 & 0.0249 & $4.3 \%$ & 0.0079 \\
\hline High & Ref. & & & & & Ref. & & & & & \\
\hline \multicolumn{12}{|c|}{ Wealth Quintile } \\
\hline $\begin{array}{l}\text { Q1 } \\
\text { (Poorest) }\end{array}$ & $-0,1888 * * *$ & -0.1830 & -0.7342 & 0.1343 & $21.24 \%$ & $-0.2423 * * *$ & -0.2043 & -0.6655 & 0.1360 & $23.2 \%$ & 0.0016 \\
\hline Q2 & $-0,1328 * * *$ & -0.1042 & -0.2506 & 0.0261 & $4.13 \%$ & $-0.1308 * * *$ & -0.1097 & -0.3092 & 0.0339 & $5.8 \%$ & 0.0078 \\
\hline Q3 & $-0,0126$ & -0.0094 & 0.0464 & -0.0004 & $-0.07 \%$ & -0.0355 & -0.0282 & 0.0314 & -0.0009 & $-0.2 \%$ & -0.0005 \\
\hline Q4 & 0,0293 & 0.0225 & 0.3392 & 0.0076 & $1.21 \%$ & 0.0092 & 0.0074 & 0.3530 & 0.0026 & $0.4 \%$ & -0.0050 \\
\hline $\begin{array}{l}\text { Q5 } \\
\text { (Richest) }\end{array}$ & Ref. & & & & & Ref. & & & & & \\
\hline $\begin{array}{l}\text { Total } \\
\text { observed }\end{array}$ & & & & 0,711 & $112 \%$ & & & & 0.5000 & $85 \%$ & \\
\hline Residual & & & & -0.0786 & $-12 \%$ & & & & 0.0851 & $15 \%$ & \\
\hline $\mathrm{ClE}$ & & & & 0.6324 & $100 \%$ & & & & 0.5852 & $100 \%$ & \\
\hline
\end{tabular}

Marginal effects statistically significantare in bold $(* \mathrm{p} \leq 0.05, * * \mathrm{p} \leq 0.01, * * * \mathrm{p} \leq 0.001)$ 
Figure 2. Decomposition of inequality in access to SBA in Mauritania and total change 2007-2015

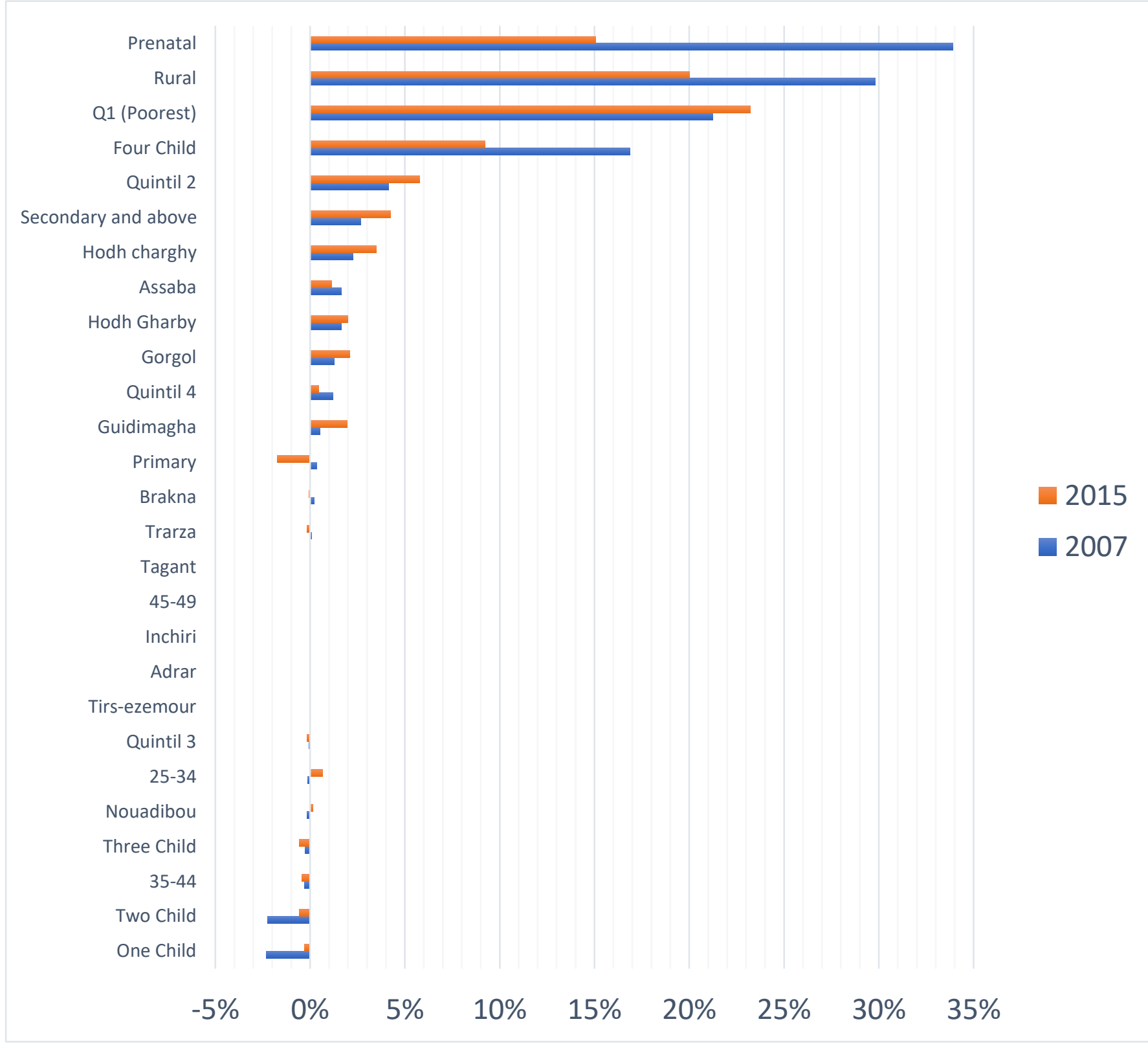

\subsection{Decomposing changes in inequality}

Oaxaca decomposition measure the extent to which the changes in CIE contributions were due to changes in elasticities or to changes in inequality of the explanative variables. Table 3 presents results for two types of Oaxaca decomposition. The second and third columns show the results based on equation 5, whereas the fourth and fifth columns demonstrate results based on equation 6. Regardless of the equation used, change in the decomposed concentration index between years 2007 and 2015 is the same as shown in the final columns (sixth and seventh columns) in the table. 
Table 3 Oaxaca-type decomposition for change in inequality, 2007-15

\begin{tabular}{|c|c|c|c|c|c|c|}
\hline & \multicolumn{2}{|c|}{ Equation 6} & \multicolumn{2}{|c|}{ Equation 7} & \multirow[b]{2}{*}{ Total $\Delta$} & \multirow[b]{2}{*}{$\% \Delta$} \\
\hline & $\begin{array}{l}\text { Weighted } \Delta \text { in } \\
\text { elasticity }\end{array}$ & $\begin{array}{c}\text { Weighted } \\
\Delta \text { in CIE }\end{array}$ & $\begin{array}{c}\text { Weighted } \\
\Delta \text { in } \mathrm{ClE}\end{array}$ & $\begin{array}{l}\text { Weighted } \Delta \text { in } \\
\text { elasticity }\end{array}$ & & \\
\hline \multicolumn{7}{|l|}{ Age } \\
\hline $15-24$ & Ref. & & & & & \\
\hline $25-34$ & 0.0029 & 0.0016 & -0.0025 & 0.0070 & 0.0045 & $-9.6 \%$ \\
\hline $35-44$ & 0.0003 & -0.0010 & 0.0002 & -0.0009 & -0.0008 & $1.6 \%$ \\
\hline $45-49$ & 0.0000 & -0.0002 & 0.0000 & -0.0003 & -0.0002 & $0.5 \%$ \\
\hline \multicolumn{7}{|l|}{ Birth order } \\
\hline Child (0) & Ref. & & & & & \\
\hline Child (1) & 0.0000 & 0.0129 & -0.0003 & 0.0132 & 0.0128 & $-27.2 \%$ \\
\hline Child (2) & 0.0009 & 0.0101 & 0.0031 & 0.0079 & 0.0110 & $-23.3 \%$ \\
\hline Child (3) & -0.0028 & 0.0012 & -0.0090 & 0.0074 & -0.0016 & $3.4 \%$ \\
\hline Child (4+) & 0.0067 & -0.0596 & 0.0152 & -0.0681 & -0.0528 & $111.8 \%$ \\
\hline \multicolumn{7}{|l|}{ Prenatal } \\
\hline yes & -0.0682 & -0.0580 & -0.0936 & -0.0327 & -0.1263 & $267.2 \%$ \\
\hline no & Ref. & & & & & \\
\hline \multicolumn{7}{|c|}{ Place of residence } \\
\hline Rural & 0.0040 & -0.0753 & 0.0066 & -0.0780 & -0.0714 & $151.1 \%$ \\
\hline Urban & Ref. & & & & & \\
\hline \multicolumn{7}{|l|}{ Region } \\
\hline Hodh charghy & 0.0016 & 0.0044 & 0.0012 & 0.0047 & 0.0060 & $-12.6 \%$ \\
\hline Hodh Gharby & -0.0005 & 0.0017 & -0.0004 & 0.0016 & 0.0012 & $-2.6 \%$ \\
\hline Assaba & -0.0024 & -0.0014 & -0.0028 & -0.0010 & -0.0038 & $8.1 \%$ \\
\hline Gorgol & -0.0006 & 0.0047 & -0.0004 & 0.0045 & 0.0042 & $-8.8 \%$ \\
\hline Brakna & 0.0002 & -0.0019 & -0.0005 & -0.0012 & -0.0017 & $3.6 \%$ \\
\hline Trarza & 0.0003 & -0.0018 & -0.0001 & -0.0013 & -0.0014 & $3.0 \%$ \\
\hline Adrar & 0.0000 & 0.0000 & 0.0000 & 0.0000 & 0.0000 & $0.0 \%$ \\
\hline Nouadibou & 0.0001 & 0.0017 & -0.0001 & 0.0018 & 0.0018 & $-3.8 \%$ \\
\hline Tagant & -0.0001 & -0.0001 & -0.0001 & 0.0000 & -0.0002 & $0.3 \%$ \\
\hline Guidimagha & 0.0046 & 0.0036 & 0.0022 & 0.0061 & 0.0082 & $-17.4 \%$ \\
\hline Tirs-Zemour & 0.0000 & 0.0000 & 0.0000 & 0.0000 & 0.0000 & $0.0 \%$ \\
\hline Inchiri & 0.0000 & 0.0000 & 0.0000 & 0.0000 & 0.0000 & $0.0 \%$ \\
\hline Nouakchott & Ref. & & & & & \\
\hline \multicolumn{7}{|c|}{ Education Level } \\
\hline Primary & -0.0145 & 0.0021 & -0.0073 & -0.0051 & -0.0123 & $26.1 \%$ \\
\hline Secondary & 0.0016 & 0.0063 & 0.0012 & 0.0068 & 0.0079 & $-16.8 \%$ \\
\hline High & Ref. & & & & & \\
\hline \multicolumn{7}{|c|}{ Wealth Quintile } \\
\hline Q1 (Poorest) & -0.0140 & 0.0157 & -0.0126 & 0.0142 & 0.0016 & $-3.5 \%$ \\
\hline Q2 & 0.0064 & 0.0014 & 0.0061 & 0.0017 & 0.0078 & $-16.5 \%$ \\
\hline
\end{tabular}




\begin{tabular}{lrrrrrr} 
Q3 & 0.0004 & -0.0009 & 0.0001 & -0.0006 & -0.0005 & $1.0 \%$ \\
Q4 & 0.0001 & -0.0051 & 0.0003 & -0.0053 & -0.0050 & $10.6 \%$ \\
Q5 (Richest) & Ref. & & & & & \\
Total & -0.0730 & -0.1380 & -0.0934 & -0.1176 & -0.2110 & $446 \%$ \\
observed & & & & & & 0.1637 \\
Residual & & & & & -0.0473 & $-346 \%$ \\
CIE & & & & & & $100 \%$ \\
\hline
\end{tabular}

The results indicate that changes in SBA inequality occur from the alteration in the interaction among the inequality regressors, where variables with positive and negative signs offsetting the inequality (seventh columns). A negative sign on a variable denotes that its contribution increases SBA inequalities over the period 2007-2015, while a positive sign indicates its contribution reduces SBA inequalities over the same period. For example, negative changes in several determinants specifically having 25-34 year old, having one or two living children residing in Guidimagha, Hodh Charghy or Gorgol, being poorest or poor and having secondary school level or above, indicate that their shares in total inequality had (noticeably) increased, thus contributing into the increase of the inequalities observed in 2015. On the contrary, the positive changes in the variables such as antenatal care use, rural residency, having four or more children, having a primary school level, being 35-49 years old pushed inequality towards equality line.

Overall, changed CIE and elasticities of the determinants contributed in a different way to the reduction in inequalities in SBA. Antenatal care use $(267,2 \%)$ account for the largest contribution to the observed decrease in inequality, which due to changes in both elasticity and the unequal distribution. Rural location $(151,1 \%)$ and having four or more living children $(111,8 \%)$ accounted also for large contributions to the observed decrease in inequality, which mainly due to changes of these two variables in elasticity rather than the unequal distribution. By contrast, changing inequalities for wealth quintiles and primary education level appear to be more important than changing elasticities.

\section{Discussion}

The present study measure and explore changes in socio-economic inequality in skilled birth attendance in Mauritania from 2007 to 2015. The main findings were as follows: i) there was a pro-rich inequality in SBA utilization in both years; ii) inequality in SBA decreased over time; iii) The main contributors to inequality in SBA utilization are antenatal care use, living in rural area, and economics status of household (i, e. being poorest (Q1) or poor (Q2)) ; iv) The rank of main contributors has changed over that period; $v$ ) improvement in antenatal care use and rural area characteristics, and having four or more children were accountable for bulk of narrowing in SBA utilization inequality in Mauritania.

Inequality in SBA utilization in Mauritania did favor advantaged women in 2007 and 2015. This finding is consistent with the results of several previous studies in Sub-Saharan African and low and middle-income countries [18-34]. Although pro-rich inequality persists, the decline by -0.047 points or -7.5 percent in inequality in SBA in Mauritania between 2007 and 2015 suggest a better performance than the average changes of inequality observed in SSA + 0.0311 points or +23.6 percent. It also suggests a better performance than the average decrease in West Africa -0.0205 points or -6.8 percent. However, this performance seems lower that the finding from Senegal -0.0916 points or -32.2 percent [52]. 
Government efforts to improve the availability and deployment of skilled birth attendants have resulted in the creation of four public health schools in rural areas since 2009. In addition, the modernization of obstetric care facilities and the doubling of number of primary health care facilities such as health posts and health centers between 2007 and 2015. Despite these efforts, the country remains far from the minimum threshold of 34.5 doctors, nurses and midwives per 10000 population that was established by WHO as necessary to deliver essential maternal and child health services [53]. Data from National Health Statistics Yearbook show an increase of the number of qualified health personnel per 10,000 people at the rural level from 2.8 per 10 000 population in 2008 to 4.7 per 10,000 people in 2015 against 5.6 and 6.3 per 10,000 people for the urban area between 2008 and 2015 respectively [54, 55]. The authors suggest that it is highly probable that governments efforts and the persistence challenging have contributed in the slight reduction of SBA inequality in Mauritania.

Decomposition approach showed that the largest contributors to inequality in SBA utilization are antenatal care use, living in rural area, and economics status of household women were the largest contributors to SBA inequality in 2007 and 2015, respectively. This finding suggests that the change in SBA inequality is most sensitive to these three important determinants. Previous studies showed a significant and similar effect of antenatal consultations on skilled birth attendance [56]. Reduction antennal care contribution to inequality (by 18.81\%) over those periods can be due to comprehensive policies targeting maternal care coverage as the first priority of the national health development plan 2012-2015. In addition, the decline in rural-urban inequality explains to some extent the reduction in SBA inequality between 2007 and 2015. The rural-urban disparity in economic level triggered many challenges in the field of healthcare, such as geographic and financial access to health services [57-71]. The rural areas in Mauritania are characterized by extremely dispersed settlement patterns and very low densities, largely the result of water scarcity, small overall populations, huge distances to health facilities and extremely low service standards. However, the recent developments in terms of rehabilitation and extension of the road network where the linear length of paved roads increased from $1,760 \mathrm{~km}$ in 2001 to $3,069 \mathrm{~km}$ in 2010 before reaching 4,867 km in $2014 \mathrm{might}$ helped to address transportation barriers to health care access particularly for rural and remote areas. In addition, in terms of health infrastructure, the number of health posts and health centers experienced an annual increase by $6 \%$ and $10 \%$ respectively between 2008 and 2015 . Consequently, geographic access to health care facility within $5 \mathrm{~km}$ which increased from $58,7 \%$ in 2008 to $82.2 \%$ in 2015 . Nevertheless, the rural service delivery concerns persist for the poorest in remote areas. Despite the overall serious shortage of health workforce which limits Reproductive, Maternal, Neonatal, Child Health and Nutrition (RMNCHN) services delivery and utilization, government resources allocated to rural areas have helped to some extent to mitigate urban-rural disparities in distribution of RMNCHN care and skilled birth attendants. Consequently, revealed reduction in the contribution of urban rural location to SBA inequality seems fathomable.

Also, the results of this study are in alignment with finding from low- and middle-income countries suggesting that wealth quintiles are main contributor of inequalities in skilled birth attendance. The finding of this study shows that despite the improvement in the country's economic situation and poverty profile during this period, the contribution of wealth index to inequality in SBA arise by 3.6 percent between 2007 and 2015. This arise trend is due to decrease in elasticity suggesting that women with this characteristic are less likely to receive skilled birth attendance at delivery. However, significant drop in the number of people living below the monetary poverty line has been observed during this period. The prevalence of poverty has fallen from $45 \%$ in 2008 to $31 \%$ in 2014[1-2]. The country has achieved large but volatile growth in recent years and has recently been classified as a lower middle-income 
country (LMIC), with a GDP per capita of US\$ 1524 in 2015 [3]. Furthermore, the country has moved up from the position of low-income country to low-middle income country during the study period. However, women in poorest and poor quintiles groups have been left behind in terms of SBA.

Several limitations of the research should be considered. Firstly, MICS surveys do not collect data on household expenditures or income but rather measure the economic situation of households by analyzing household assets and housing characteristics and create assetsbased Wealth Index. Secondly, distance to health facility were not evaluated as they were not captured during the surveys. Thirdly, MICS surveys do not collect data on Health protection (insurance, free health care, etc.) in Mauritania. However, voluntary insurance scheme covering maternal health costs in public health facilities was collected only in 2015 and not captured before. Its contribution in inequality was measured and seems to be limited 5\%. The lack of data on this scheme in the surveys preceding to 2015 prevents us from measuring the contribution of this variable to the change in inequality over time and has led us to its exclusion from the analysis. Finally, the number of antenatal visits was not captured in 2007 survey, which not allowed us to use the fourth prenatal visits as the variable for prenatal care.

\section{Conclusion}

Despite their great need, poor women tended to use SBA services to lesser extent than wealthy women. The concentration curves diverge from the line of equality and the concentration indices were significantly different from zero showing a pro-rich distribution for all surveys covered by the research. The main contributors to the pro-rich inequality in SBA were nonneed factors such as: wealth index, geographic location, women's level of education, and number of living children. This pattern harms the basic requirements for equity of access to SBA services, namely women with the same health needs should have similar access to health care services.

In addition, time-trend revealed a relatively small narrowing of the gap between the richest and the poorest. Wealth index widely affects maternal health care use. The place of residence of women and the level of education influence maternal health care use to an important but lesser extent than wealth index. Furthermore, Oaxaca decomposition analysis suggests that the decrease in pro-rich inequalities in SBA is mainly due to the decreased disparities between urban and rural areas and antennal care.

Therefore, this study recommends policies that promote development focused on eliminating the gaps between rich and poor. Clearly, a concerted multisectoral approach in line with the principles of the Primary health Care focus is needed to improve social determinants of health, including women and girls' economic empowerment, and to enhance availability of skilled birth attendants in rural area as well as distribution and quality of health infrastructure particularly health posts and health centers. Besides, removing user fees and improving social health protection will support a better financial access to SBA services. Other areas of intervention include communication for behavioral change and considering cultural factors that are one of the challenges to improve utilization to reproductive health services.

This research found that inequalities are still high. Further researches are needed to measure the burden of out of Pocket payments on affordability of maternal health care including catastrophic health payment and impoverishing health payment. 


\section{References}

1. National Office of Statistics. Report of the 2008 Permanent Survey of Household Living Conditions. [Rapport de l'Enquête permanente sur les conditions de vie des ménages 2008]. Nouakchott : National Office of Statistics; 2009

2. National Office of Statistics. Report of the 2014 Permanent Survey of Household Living Conditions. [Rapport de l'Enquête permanente sur les conditions de vie des ménages 2014]. Nouakchott : National Office of Statistics; 2015

3. World Bank. Poverty Dynamics and Social Mobility 2008-2014. Washington: World Bank; 2016.

4. National Office of Statistics. General Census of Population and Housing 2013: mortality. [Recensement Général de la Population et de l'Habitat 2013 : mortalité]. Nouakchott : National Office of Statistics; 2015

5. Programme des nations unies pour le développement. Rapport sur le progrès dans la mise en œuvre des objectifs du millernaire pour le developpement en Maurtanie. [Internet]. 2008. [Cited 2008 Aug 3]; available from: https://www.undp.org/content/dam/undp/library/MDG/english/MDG\%20Country\%20Repo rts/Mauritania/RapportOMD2008Mauritanie.pdf . 28 p.

6. Trends in maternal mortality 2000 to 2017: estimates by WHO, UNICEF, UNFPA, World Bank Group and the United Nations Population Division. Geneva: World Health Organization; 2019. Licence: CC

7. World Bank. World Bank Open Data. available from: https://data.worldbank.org/indicator/EN.POP.DNST?locations=ZG

8. Ministry of Health. National health development plan preparation process (2012-2020): Health sector situation analysis report. [Processus d'élaboration du plan national de développement sanitaire (2012-2020) : Rapport d'analyse de situation du secteur de la sante]. Nouakchott: Ministry of Health; 2011

9. Ministry of Health. Service Availability and Readiness Assessment survey 2018. [Indice de disponibilité et de capacité opérationnelle des services de santé 2018]. Nouakchott: Ministry of Health; 2019

10. Maria-Pia Waelkens, Yves Coppieters, Samia Laokri and Bart Criel. An in-depth investigation of the causes of persistent low membership of community based health insurance: a case study of the mutual health organisation of Dar Naïm, Mauritania. Health Services Research. 2017; 17:535

11. Aline Philibert, Marion Ravit, Valery Ridde, Ines Dossa, Emmanuel Bonnet, Florent Bedecarrats and Alexandre Dumont. Maternal and neonatal health impact of obstetrical risk insurance scheme in Mauritania: a quasi-experimental before-and-after study. Health Policy and Plan. 2017; 32:405-417

12. Ministry of Health. Evaluation report of the first phase of the National health development plan (2012-2020). [2016 Rapport d'évaluation de la première phase du NHDP (2012-2015)]. Nouakchott : Ministry of Health; 
13. World Health Organization. Global health expenditure database [Internet]. Geneva: World Health Organization; 2017; [cited 2017 Dec 8]. Available from: http://apps.who.int/nha/database

14. United Nations. Sustainable Development Goals Volunteer - Mauritania [Internet] [Volontaire des Objectifs de Développement Durable - Mauritanie]. Available from: https://sustainabledevelopment.un.org/content/documents/23447Mauritania_REVISED_AS _OF_24JUNERevueNationalVolontaire_Mauritanie2_medium.pdf

15. Ministry of Health. The National Health Development Plan 2012-2020. [Plan National de Développement Sanitaire 2012-2020]. Nouakchott: Ministry of Health; 2012

16. Ministry of Economy and Finance. National Strategy for Accelerated Growth and Shared Prosperity 2016-2030 [Stratégie Nationale de Croissance Accélérée et de Prospérité Partagée 2016-2030]. Nouakchott: Ministry of Economy and Finance; 2017

17. World Health Organization. Making pregnancy safer: the critical role of the skilled attendant: a joint statement by WHO, ICM and FIGO. Geneva: World Health Organization; 2004. $1 \mathrm{p}$.

18. Rifkatu Nghargbu and Olanrewaju Olaniyan. Inequity in Maternal and Child Health Care Utilization in Nigeria African Development Review, Vol. 29, No. 4, 2017, 630-647

19. Simon M Collin, Iqbal Anwar and Carine Ronsmans. A decade of inequality in maternity care: antenatal care, professional attendance at delivery, and caesarean section in Bangladesh (1991-2004). International Journal for Equity in Health 2007, 6:9

20. Van Malderen et al. Decomposing Kenyan socio-economic inequalities in skilled birth attendance and measles immunization. International Journal for Equity in Health 2013, 12:3

21. Zere et al. Inequities in skilled attendance at birth in Namibia: A decomposition analysis. BMC Pregnancy and Childbirth 2011, 11:34

22. Abekah-Nkrumah.Trends in utilisation and inequality in the use of reproductive health services in Sub- Saharan Africa BMC Public Health (2019) 19:1541

23. Zere et al. Inequities in skilled attendance at birth in Namibia: A decomposition analysis. BMC Pregnancy and Childbirth 2011, 11:34

24. Gebre et al. Inequities in maternal health services utilization in Ethiopia 2000-2016: magnitude, trends, and determinants Reproductive Health (2018) 15:119

25. Goland et al. Inequity in maternal health care utilization in Vietnam. International Journal for Equity in Health 2012, 11:24

26. Bronwyn Harrisa, ${ }^{*}$, Jane Goudgea, John E. Atagubab, Diane McIntyreb, Nonhlanhla Nxumaloa, Siyabonga Jikwanac, and Matthew Chersich Inequities in access to health care in South Africa. Journal of Public Health Policy 2011 Vol. 32, S1, S102-S123

27. Joseph G, da Silva ICM, Barros AJD, et al. Socioeconomic inequalities in access to skilled birth attendance among urban and rural women in low-income and middle-income countries. BMJ Glob Health 2018;3:e000898. doi:10.1136/ bmjgh-2018-000898

28. Dipty Nawal Srinivas Goli , (2013),"Inequalities in utilization of maternal health care services in Nepal", Ethnicity and Inequalities in Health and Social Care, Vol. 6 Iss 1 pp. 3-15

29. M.N. Khan a, *, M.M. Islam b,c, M.M. Rahman. Inequality in utilization of cesarean delivery in Bangladesh: a decomposition analysis using nationally representative data. public health 157 (2018) 111e120

30. Mats Målqvist, Asha Pun, Hendrikus Raaijmakers \& Ashish KC (2017) Persistent inequity in maternal health care utilization in Nepal despite impressive overall gains, Global Health Action, 10:1, 1356083, DOI: 10.1080/16549716.2017.1356083

31. Mezmur et al. Socioeconomic inequalities in the uptake of maternal healthcare services in Ethiopia. BMC Health Services Research (2017) 17:367 
32. Molina HF, Nakamura K, Kizuki M, et al. Reduction in inequality in antenatal-care use and persistence of inequality in skilled birth attendance in the Philippines from 1993 to 2008. BMJ Open 2013;3: e002507. doi:10.1136/ bmjopen-2012-002507

33. RAMA PA. Inequality in Maternal Health Care Utilization In India: A Shapley Decomposition Analysis? J. Int. Dev. 27, 1141-1152 (2015)

34. Gordon Abekah-Nkrumah. Trends in utilisation and inequality in the use of reproductive health services in Sub- Saharan Africa. BMC Public Health (2019) 19:1541; https://doi.org/10.1186/s12889-019-7865-z

35. Amporfu, E., Grépin, K.A. Measuring and explaining changing patterns of inequality in institutional deliveries between urban and rural women in Ghana: a decomposition analysis. Int J Equity Health 18, 123 (2019). https://doi.org/10.1186/s12939-019-1025-z

36. Ambel, A.A., Andrews, C., Bakilana, A.M. et al. Examining changes in maternal and child health inequalities in Ethiopia. Int J Equity Health 16, 152 (2017). https://doi.org/10.1186/s12939-017-0648-1

37. National Office of Statistics. Multiple Indicator Cluster Survey (MICS) 2007. [Enquête par Grappes à Indicateurs Multiples (MICS) 2007]. Nouakchott: National Office of Statistics; 2007

38. National Office of Statistics. Multiple Indicator Cluster Survey (MICS) 2015. [Enquête par Grappes à Indicateurs (MICS) 2015]. Nouakchott : National Office of Statistics; 2016

39. Wagstaff, Adam \& van Doorslaer, Eddy \& Paci, Pierella, 1991. "On the measurement of horizontal inequity in the delivery of health care," Journal of Health Economics, Elsevier, vol. 10(2), pages 169-205, July.

40. Wagstaff $A$. The bounds of the concentration index when the variable of interest is binary, with an application to immunization inequality. Health Econ. 2005 Apr;14(4):429-32. doi: 10.1002/hec.953. PMID: 15495147.

41. Wagstaff $A$. The bounds of the concentration index when the variable of interest is binary, with an application to immunization inequality. Health Econ. 2005;14:429-32

42. Errygers, G. (2009a). Correction the concentration index. Journal for health economics 12 , 511-516.

43. Erreygers $G$, Van Ourti T. Measuring socioeconomic inequality in health, health care and health financing by means of rank-dependent indices: a recipe for good practice. J Health Econ. 2011 Jul;30(4):685-94. doi: 10.1016/j.jhealeco.2011.04.004. Epub 2011 May 11. PMID: 21683462; PMCID: PMC3158909.

44. Wagstaff A. Correcting the concentration index: a comment. J Health Econ. 2009 Mar;28(2):516-20, author reply 521-4. doi: 10.1016/j.jhealeco.2008.12.003. Epub 2008 Dec 24. PMID: 19167117.

45. Erreygers G, Van Ourti T. Putting the cart before the horse. A comment on Wagstaff on inequality measurement in the presence of binary variables. Health Econ. 2011 Oct;20(10):1161-5. doi: 10.1002/hec.1754. Epub 2011 Jun 15. PMID: 21674679; PMCID: PMC3304083.

46. Kakwani N, Wagstaff A, Van Doorslaer E. Socioeconomic inequalities in health: measurement, computation, and statistical inference. J Econ. 1997;77:87-103.

47. Wagstaff A, van Doorslaer E, Watanabe N. On decomposing the causes of health sector inequalities with an application to malnutrition inequalities in Vietnam. J Econ. 2003;112:207-23.

48. Hangoma P, Aakvik A, Robberstad B (2017) Explaining changes in child health inequality in the run up to the 2015 Millennium Development Goals (MDGs): The case of Zambia. PLoS ONE 12 (2): e0170995. doi:10.1371/journal.pone.0170995 
49. Khaled MA, Makdissi P, Tabri RV, Yazbeck M. A framework for testing the equality between the health concentration curve and the 45-degree line. Health Econ. 2018;27(5):887-896.

50. Kjellsson, Gustav \& Gerdtham, Ulf-G. (2014). Measuring Health Inequalities Using the Concentration Index Approach. 10.1016/B978-0-12-375678-7.00206-6.

51. StataCorp. 2017. Stata Statistical Software: Release 15. College Station, TX: StataCorp LLC.

52. Gordon Abekah-Nkrumah. Trends in utilisation and inequality in the use of reproductive health services in Sub- Saharan Africa. BMC Public Health (2019) 19:1541; https://doi.org/10.1186/s12889-019-7865-z

53. World Health Organization. What are the latest statistics on health workforce availability? Why does the latest HRH report (A Universal Truth - No health without a Workforce, 2013) use a different threshold (33.45/10'000) from the WHO 2006 report(22.8/10'000)?. Available from: https://www.who.int/workforcealliance/media/qa/05/en/

54. Ministry of Health. Statistical yearbook. [L'annuaire statistiques 2015]. Nouakchott : Ministry of Heath ; 2016

55. Ministry of Health. Statistical yearbook. [L'annuaire statistiques 2012]. Nouakchott : Ministry of Heath ; 2013

56. Vissého Adjiwanoua, $b$ and Thomas Le Grand. Does antenatal care matter in the use of skilled birth attendance in rural Africa: A multi-country analysis. 2013 Elsevier. Social Science \& Medicine 86 (2013) $26 \mathrm{e} 34$

57. Gebre, Emebet \& Worku, Alemayehu \& Bukola, Fawole. (2018). Inequities in maternal health services utilization in Ethiopia 2000-2016: Magnitude, trends, and determinants. Reproductive Health. 15. 119. 10.1186/s12978-018-0556-x.

58. Goland, Emilia \& Hoa, Dinh \& Målqvist, Mats. (2012). Inequity in maternal health care utilization in Vietnam. International journal for equity in health. 11. 24. 10.1186/1475-927611-24.

59. Zere E, Oluwole D, Kirigia JM, Mwikisa CN, Mbeeli T. Inequities in skilled attendance at birth in Namibia: a decomposition analysis. BMC Pregnancy Childbirth. 2011;11:34. Published 2011 May 14. doi:10.1186/1471-2393-11-34

60. Dipty Nawal Srinivas Goli , (2013),"Inequalities in utilization of maternal health care services in Nepal", Ethnicity and Inequalities in Health and Social Care, Vol. 6 Iss 1 pp. $3-15$

61. Joseph G, da Silva ICM, Barros AJD, et al. Socioeconomic inequalities in access to skilled birth attendance among urban and rural women in low income and middle-income countries. BMJ Glob Health 2018;3: e000898

62. Khan, Nuruzzaman \& Islam, M. Mofizul \& Rahman, Mijanur. (2018). Inequality in utilization of cesarean delivery in Bangladesh: a decomposition analysis using nationally representative data. Public health. 157. 111-120. 10.1016/j.puhe.2018.01.015

63. Liu, X., Gao, W. \& Yan, H. Measuring and decomposing the inequality of maternal health services utilization in Western Rural China. BMC Health Serv Res 14, 102 (2014). https://doi.org/10.1186/1472-6963-14-102

64. Mats Målqvist, Asha Pun, Hendrikus Raaijmakers \& Ashish KC (2017) Persistent inequity in maternal health care utilization in Nepal despite impressive overall gains, Global Health Action, 10:1, 1356083, DOI: 10.1080/16549716.2017.1356083

65. Mezmur, M., Navaneetham, K., Letamo, G. et al. Socioeconomic inequalities in the uptake of maternal healthcare services in Ethiopia. BMC Health Serv Res 17, 367 (2017). https://doi.org/10.1186/s12913-017-2298-9

66. Molina HF, Nakamura K, Kizuki M, et al. Reduction in inequality in antenatal-care use and persistence of inequality in skilled birth attendance in the Philippines from 1993 to 2008. BMJ Open 2013;3: e002507. doi:10.1136/ bmjopen-2012-002507 
67. Nwosu, C.O., Ataguba, J.E. Socioeconomic inequalities in maternal health service utilisation: a case of antenatal care in Nigeria using a decomposition approach. BMC Public Health 19, 1493 (2019). https://doi.org/10.1186/s12889-019-7840-8

68. Omani-Samani, Reza \& Amini-Rarani, Mostafa \& Sepidarkish, Mahdi \& Khedmati Morasae, Esmaeil \& Maroufizadeh, Saman \& Almasi-Hashiani, Amir. (2018). Socioeconomic inequality of unintended pregnancy in the Iranian population: a decomposition approach. BMC Public Health. 18. 10.1186/s12889-018-5515-5.

69. R. Nghargbu, O. Olaniyan Inequity in Maternal and Child Health Care Utilization in Nigeria African Development Rev, 29 (4) (2017), pp. 630-647

70. Collin, S.M., Anwar, I. \& Ronsmans, C. A decade of inequality in maternity care: antenatal care, professional attendance at delivery, and caesarean section in Bangladesh (1991-2004). Int J Equity Health 6, 9 (2007). https://doi.org/10.1186/1475-9276-6-9

71. Khadr Z. Monitoring socioeconomic inequity in maternal health indicators in Egypt: 19952005. Int J Equity Health [Internet]. 2009 Nov 8 [cited 2017 Dec 15];8:38. 